\title{
A Further Study on the Left-Right Asymmetry of the Planum Temporale
}

\author{
By \\ Keiji TAKAMI, Akira SAKURAI, Fumio MUKAI* and Takashi YAMADORI \\ First Department of Anatomy, Kobe University School of Medicine, Kusunoki-cho 7-chome 5-1, Chuo-ku, Kobe 650,
Japan
*Department of Animal Breeding, Kobe University Faculty of Agriculture, Rokkodai-cho, 1-1, Nada-ku, Kobe 650,
Japan \\ - Received for Publication, February 25, $1993-$ \\ Key Words: Planum temporale, Speech arca, Left-right asymmetry, Rubbed copy method, Japanese adult

\begin{abstract}
Summary: By means of a rubbed copy method using India ink and an image-analysis system (IBAS 2000), the areas of 106 left-right plana temporalia were compared using fixed brains of both sexes. The left planum was of a larger size than the right planum in two-thirds of the cases. This result was confirmed statistically by the least-squares analysis of variance method $(\mathbf{p}<\mathbf{0 . 0 1})$.
\end{abstract}

Morphological differences in the planum temporale, which is located on the superior surface of the temporal lobe and is thought to be an important part of the cortical speech area, had been reported in the early decades of this century (Flechsig, 1908; Pfeifer, 1920; Kakeshita, 1925; Economo and Horn, 1930). Then, little attention was paid to this area until 1968 when Geschwind and Levitsky examined this area quantitatively and reported that the left planum was significantly larger than the right one. Since then, a number of reports based upon various methods of measurements followed and confirmed the results of Geschwind and Levitskey (Witelson and Pallie, 1973; Wada et al., 1975, Yamadori et al., 1982; Falzi et al., 1982). Other studies proved the left-right difference of other cortical regions which are considered to be associated with the sensory speech area, for example, the area comprising the superior part of the superior temporal gyrus, angular gyrus and the supramarginal gyrus (Yamadori et al., 1978) and the opercular part of the inferior frontal gyrus (Wada et al., 1975; Falzi et al., 1982). The purpose of the present study is to reexamine the left-right difference of the planum temporale more precisely using a large number of human brains than reported previously (Yamadori et al. 1982).

\section{Materials and Method}

One hundred and six adult Japanese brains fixed in $10 \%$ formalin were used. These brains had no gross anatomical defects or deformations, and were subsequently used in the medical student dissection course. Seventy-three brains were from male and 33 were from female cadavers. Their age ranged from 21 to 91 years with the mean age 61.62 years (male: 58.47, female: 68.61 ). Each brain was washed for 5 to 7 days in running tap water, weighed, and then the arachnoid mater and pia mater were removed along with the surface blood vessels. The medulla and pons with attached cerebellum were removed from the caudal end of the midbrain and the left and right cerebral hemispheres were separated at the midsagittal plane using a brain-knife. The temporal lobe was then isolated by cutting along the posterior branch of the lateral sulcus to expose the superior surface of the temporal lobe where the planum temporale is located. The covering meninges and blood vessels on this surface were also removed and the surface of the brain was blotted using filter paper. The blotted surface of the planum and its surroundings were painted with a mixture of thick India ink and a small amount of starch. A rubbed copy was obtained by laying a piece of thin Japanese paper, which is good for the printing by the ink, onto the painted surface of the planum temporale and pressing it gently against the surface with a cotton tampon. Thus, the exact shape of the planum and the neighboring gyri appeared on the surface of the paper as a positive picture (Yamadori et al., 1978). Then the borderline of the planum was delineated (Fig. 1). The contour of the planum was redrawn 
onto tracing paper and the areas of the left and right plana were measured at the same time automatically using the IBAS 2000 image analysis system. The least-squares analysis of variance method was used for comparison of the area of the planum. Sex and side (left or right) were included in a statistical model as the fixed effects, and age and brain weight as the covariates.
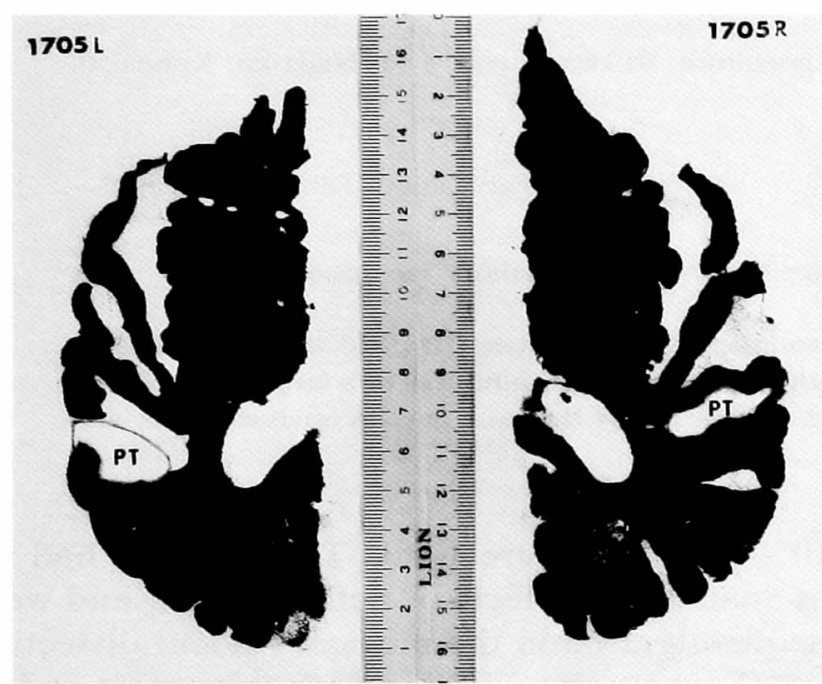

Fig. 1. India ink-rubbed copies of bilateral plana temporalia. PT: planum temporale

\section{Results}

The mean area of the planum temporale of all cases was appoximately $400 \mathrm{~mm}^{2}$ on the left side and $300 \mathrm{~mm}^{2}$ on the right side. In about two thirds of cases, the left planum was larger in size than the right one of the same brain. The right planum, however, was larger in one-third of cases. The mean standard deviation was larger in the right (187.4) than in the left planum (143.9) (Table I).

The left and right areas of the planum in each brain were compared using a histogram (Fig. 2). The mode of the area of left planum was in an interval one step lower than that of the total mean $(366.0 \mathrm{~mm})$.

The right planum was not present in 10 cases $(9 \%)$, while the left planum was absent in only one case. The least-squares analysis of variance showed a significant difference of area between the left and right plana $(p<0.01)$. Otherwise, there were no

Table 1. Mcan areas of the planum temporale in the left and right cerebral hemispheres

\begin{tabular}{lrrr}
\hline & Number & Left planum & Right planum \\
\hline Total & 106 & $407.8 \pm 143.9$ & $324.2 \pm 187.4$ \\
Male & 73 & $423.3 \pm 146.9$ & $334.1 \pm 187.2$ \\
Female & 33 & $373.4 \pm 130.5$ & $302.1 \pm 186.0$
\end{tabular}

$($ mean $\pm S D) \mathrm{mm}^{2}$

number

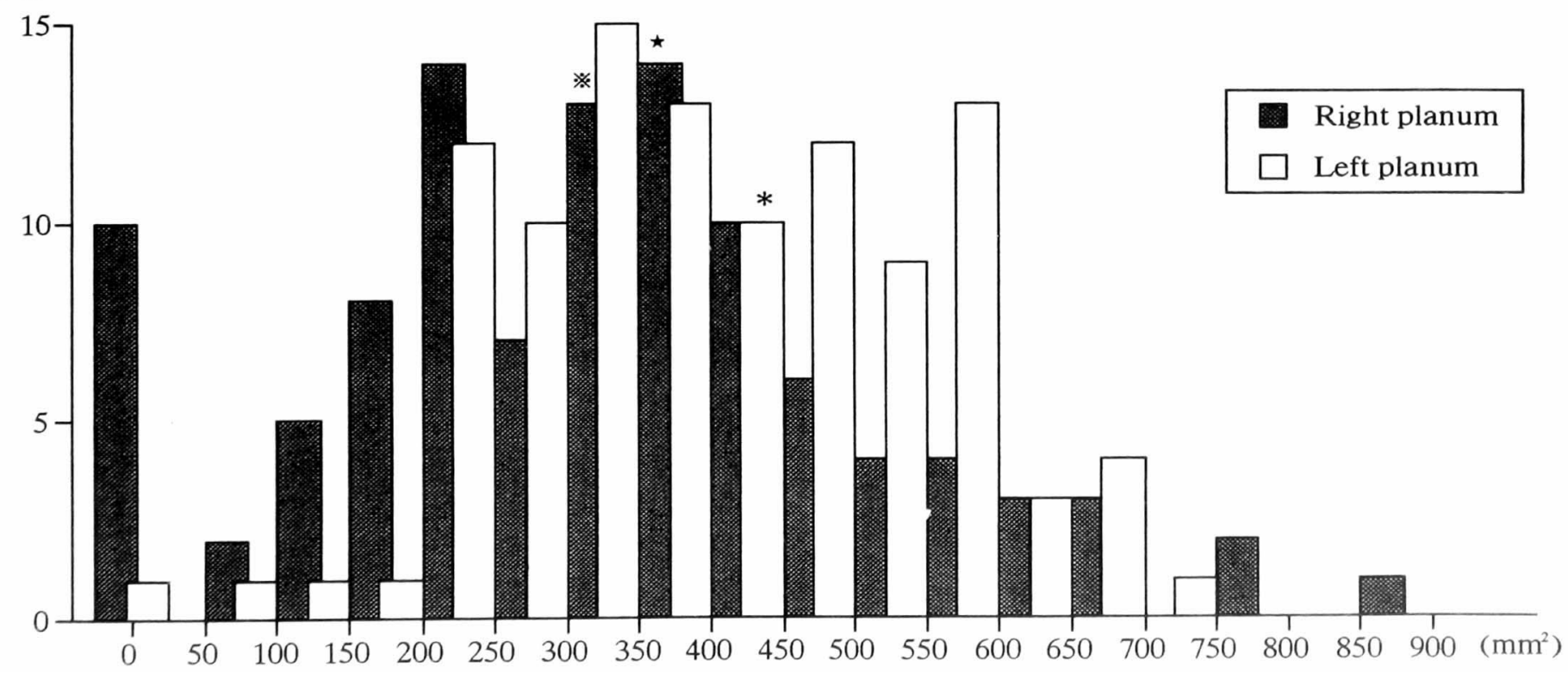

Fig. 2. Histogram of the areas of the left and right plana temporalia. Bars drawn on zero indicate brain numbers which have no planum

* :the mean of left planum

* :the mean of right planum

* :the mean of left and right plana 
significant differences between other effects considered in the statistical model.

\section{Discussion}

The left-right asymmetry of the planum temporale was studied by many investigators using various methods. Geschwind and Levitsky (1968) measured the length of the planum at the lateral edge of the lateral sulcus, while Teszner et al. (1972) measured its size by making plastic models of the planum. Witelson and Pallie (1973) used a method to measure the size of the planum from photographs, while Hori (1976) used a method to assume the area from the arterial landmark using angiographs of patients. Rubens et al. (1976) measured the length of the planum and reported that it was larger in the left hemisphere in $67 \%$ of the examined brains. Chi et al. (1977) inspected the serial celloidin sections of the planum and estimated its size approximately. However, all these methods have same defects in accuracy as they did not measure the area of the planum directly. The method used in the present study is to measure the area more accurately using a rubbed India ink copy of the planum temporale. By this method it is possible to obtain a much more accurate figure of the area. The measurement of the area was then performed using an image analysis system (IBAS 2000, Carl Zeiss).

Among the 106 brains examined in the present study, $67(63.2 \%)$ showed a larger left planum. This result generally agrees with those of previous reports. As it had been verified histologically that the size of the auditory cytoarchitectonic area generally corresponds to the size of the planum (Galaburda et al., 1978), the fact elucidated in the present study confirms that there is clear left-right asymmetry in this speech-related area of adult Japanese brains. It had been reported that almost all the right handed people have the speech-dominance in the left hemisphere, while only $70 \%$ of the left handed or mixed handed people have the dominance in the left hemisphere. Fifteen percent of those people have the dominance in the right hemisphere and the rest of 15 percent in both hemispheres (Rasmussen and Milner, 1977). The asymmetry of the planum and the handedness is an interesting theme which should be studied as the next step. We are presently compiling the brains which have unequivocal life histories of the handedness.

\section{Acknowledgements}

The authors express their appreciation to Prof. Peter J. Hand, Department of Animal Biology, University of Pennsylvania School of Veterinary Medicine, and Dr. Hanie A. Rahman, First Department of Anatomy, Kobe University School of Medicine, for reading the manuscript, and Mr. Tomiyoshi Setsu for the fine table and graph.

\section{References}

1) Chi, J. G., Dooling, E. C. and Gilles, F. H.: Left-right asymmetries of the temporal speech areas of the human fetus, Arch. Neurol., 34: 346-348, 1977.

2) Economo, C. v. and Horn, L.: Ueber Windungsrelief, Masse und Rindenarchitektonik der Supratemporalflaeche, ihre indiviuellen und ihre Seitenunterschiede, Z. f. ges. Neurol. Psychiat., 130: 678-757, 1930.

3) Falzi, G., Perrone, P., Vignolo, L. A.: Right-left asymmetry in anterior speech region, Arch. Neurol., 39: 239-240, 1982.

4) Flechsig, P.: Bemerkungen ueber die Hoersphere des menschlichen Gehirns, Neurol. Zbl., 27: 2-7, 1908.

5) Galaburda, A. M., Sanides, F. and Geschwind, N.: Human brain. Cytoarchitectonic left-right asymmetries in the temporal speech region, Arch. Neurol., 35: 812-817, 1978.

6) Geschwind, N. and Levitsky, W.: Human brain. Left-right asymmetries in temporal speech region, Science, 161: 186-187, 1968.

7) Hori, T.: Hemispheric asymmetry in living man, Brain and Nerve (Tokyo), 28: 639-649, 1976.

8) Kakeshita, T.: Zur Anatomie der operkularen Temporalregion, Arb. neurol. Inst. Univ. Wien, 27: 292-326. 1925.

9) Pfeifer, R. A.: Myelogenetisch-anatomische Untersuchungen ueber das kortikale Ende der Hoerleitung (cited by Kakeshita 1925). Abh. saechs. Akad.d. Wissensch., 37, Teubner, Leipzig, 1920.

10) Rasmussen, T. and Milner, B.: The role of early left-brain injury in determining lateralization of cerebral speech functions, Ann. N.Y. Acad. Sci.. 299: 355-369, 1977.

11) Rubens, A. B., Mahowald, M. W. and Hutton, J. T.: Asymmetry of the lateral (sylvian) fissures in man, Neurology, 26: $620-624,1976$.

12) Teszner, D., Tzavaras, A., Grunner, J. et Hècaen, H.: L'asymetric droite-gauche du planum temporale; a propos de l'etude anatomique de 100 cerveaux, Revue Neurologique, 126: 444-449, 1972.

13) Wada, J. A., Clarke, R. and Hamm, A.: Cerebral hemispheric asymmetry in humans. Cortical speech zones in 100 adult and 100 infants brains, Arch. Neurol., 32: 239-246, 1975.

14) Witelson, S. F. and Pallie, W.: Left hemisphere specialization for language in the newborn. Neuroanatomical cvidence of asymmetry, Brain, 96: 641-646, 1973.

15) Yamadori, T., Ohnishi, M.. Sukekawa. K. and Umetani, T.: A quantitative study on the left-right asymmetry in the area consisting of the posterior part of the superior temporal gyrus, the angular gyrus and the supramarginal gy'rus, Acta Anat. Nippon., 53: 180-185, 1978.

16) Yamadori, T., Sukckawa K., Umetani, T. and Yamadori. A.: A quantitative study on the left-right asymmetry of the planum temporalc. Okajima Folia Anat. Jpn., 56: 627-6.31. 1982. 